\title{
PHENOLOGY AND LIFE HISTORY OF THE FILMY DOME SPIDER (ARANEAE: LINYPHIIDAE) IN TWO LOCAL MARYLAND POPULATIONS*
}

\author{
By David H. Wise \\ Department of Biological Sciences \\ University of Maryland Baltimore County (UMBC) \\ Catonsville, MD 21228
}

\begin{abstract}
INTRODUCTION
The filmy dome spider Neriene radiata (Walckenaer) [= Liny phia (Prolinyphia) marginata C. L. Koch; Araneae, Linyphiidae] spins a fine, dome-shaped web in the understory vegetation of temperate forests. Early accounts suggested that this species has a typical annual life cycle; however, later research uncovered indirect evidence of a mixed life-history pattern in a Michigan population of $N$. radiata (Wise 1976). Seasonal changes in composition of this population strongly suggested that some hatchlings emerging from egg sacs laid in the spring developed rapidly, matured by August and reproduced before the end of the season. Other progeny of springmaturing adults apparently displayed a typical annual life cycle, over-wintering as juveniles and maturing the next spring. Since this type of life cycle had not been reported often for spiders, I decided to explore it in more depth.

The research reported here had two major goals:

1) To describe the phenologies of two different local populations of $N$. radiata in Maryland, and to compare them with the phenology of the more northern Michigan population. Such a comparison would indicate whether or not the length of the growing season might influence the species' life history pattern.

2) To obtain direct proof of two types of juveniles in the population at the end of the spring reproductive period-rapid developers, and those that over-winter before becoming mature. The goal was to confirm the previous interpretation of the observed phenology, which was based upon indirect, nonexperimentally derived evidence.
\end{abstract}

*Manuscript received by' the editor August I, 1984 


\section{METHODS}

The research, conducted at two sites $35 \mathrm{~km}$ apart, involved censusing undisturbed areas, manipulating the age structure of one population in a field experiment, and rearing field-collected juveniles from both populations.

\section{Study Sites}

The terrain of the oak forest on the Liberty Watershed, $40 \mathrm{~km}$ northwest of Baltimore, Maryland, was hilly, with rocky outcroppings, fallen trees and small saplings offering a variety of substrates for $N$. radiata to attach its web. A population at the Liberty site, on a south-facing slope at $180 \mathrm{~m}$ elevation, was studied 1980-82.

The Patuxent site was located south of Liberty on the Patuxent Wildlife Research Center near Laurel, Maryland, at an elevation of $40 \mathrm{~m}$. The oak forest at Patuxent differed from that at Liberty by having several beech and some pines. The terrain was flatter, with no rocky outcroppings and with a floristically less diverse understory. Much of the Patuxent ground cover was Vacunium sp. Relatively rare at Patuxent before 1980 , the filmy dome spider was more common 1981-82. During these years several studies were done with the Patuxent population.

\section{Determining the Phenological Pattern in Maryland Populations}

During 1980-82 I monitored seasonal changes in the size-class structure of the Liberty population by repeatedly censusing 13 areas marked with short, inconspicuous stakes. At Patuxent 8 similarly marked areas were censused, but in 1982 only. Mature $N$. radiata were collected at Liberty (spring, 1980-81; summer, 1980) and Patuxent (spring and summer, 1981-82) by capturing every adult encountered during a search of vegetation in the vicinity of the areas set aside for censusing. These spiders provided data on yearly and seasonal changes in size at maturity and fecundity. Collected adults were anesthetized briefly with $\mathrm{CO}_{2}$, measured and then paired in jars kept in the laboratory $(1980-81)$ or on a covered, screened porch in the forest at Patuxent (1982). The spiders were fed fruit flies ad lib. Females deposited an egg sac within one to several days after being collected. Each sac was removed, eggs were counted and the diameters of 10 eggs were measured with an ocular micrometer. In 1982 all the eggs from a sac were then placed in a $7 \times$ $10 \mathrm{~mm}$ plastic vial and its open end was plugged with silk from the egg sac. The vial was placed in a humid jar, where the eggs were left 
to develop. Many females continued to feed and deposited additional sacs. However, because the frequency of multiple clutches in nature is unknown, data are given for the first sac only.

Temperatures of web sites were recorded concurrently at Patuxent and Liberty with thermocouple probes on 24 May and 8 June, 1983. Each probe was covered with black tape, so that its temperature closely approximated the internal temperature of a filmy dome spider exposed to solar radiation (personal obs.). Sites selected for recording temperature originally had a $N$. radiata web and, as a group, spanned the range of exposure to wind and sunlight of webs at each study site.

\section{Direct Evidence for Different Rates of Development}

Field Experiment

During the last half of the season, $N$. radiata populations characteristically contain all stages. This diversity makes it difficult to follow the growth and development of groups of juveniles. Therefore, a manipulative field experiment was designed to facilitate monitoring of the developmental pattern of the younger spiders in the population.

Eight experimental units were placed at least $10 \mathrm{~m}$ apart in the undergrowth at Patuxent. Made of wood stakes that supported undulating pieces of $5.1 \mathrm{~cm}$-mesh galvanized wire fencing (chicken wire), each unit was $3 \mathrm{~m}$ long, $1 \mathrm{~m}$ wide and $1 \mathrm{~m}$ high. Use of these standardized units made it possible to establish open, replicated populations of similar densities and microclimatic conditions, and also facilitated identification of the experimental populations.

From 8-17 July 1981, filmy dome spiders were removed from the units and from surrounding vegetation. The smaller instars, all of which had emerged from egg sacs laid by spring-maturing females, were then added at random to the cleared units. On 21 July (Day 0 of the experiment) each unit contained $20-39$ spiders $(\bar{x}=30 \pm 2)$, all estimated to be stages $2-4$. This range represented the youngest instars in the Patuxent population on that date.

Four randomly selected populations received supplemental prey from 21 July through 28 August. On 21 days each spider was given a living fruit fly; on 5 of these days each spider was given another fly during a second round of feeding.

The 8 populations were censused frequently. At each census all mature spiders were removed and measured. Very small spiders that were obvious immigrants were also removed. Censusing of all units 
continued for 17 days after supplemental feeding had ceased, and on 14 September the experiment was terminated by removing and measuring all remaining spiders.

\section{Rearing Field-Collected Juveniles}

A major advantage of the field experiment was that biotic and physical factors that limit growth and development were at natural levels. However, because the populations were open the developmental fates of individual spiders could not be monitored without error. More direct evidence of the variable developmental fates of the progeny of spring adults was obtained by collecting spiders from natural populations and rearing them individually to the end of the season or until they had matured.

On 1 July 1980, 47 of the largest juveniles in the population were collected from Liberty. This collection included those offspring of spring adults most likely to complete development and reproduce that summer. In the following year a different sampling strategy was employed. In 1981, 89 of the smallest spiders (stages 1-3) in the Liberty population were collected on 6 July. These were the progeny of spring adults least likely to complete development within the season. I sampled the extemes of the size distribution in order to uncover the limits to the developmental potential of the population at a particular time. Logistical constraints prevented sampling of the entire range of size classes in a single season.

In 1982 juvenile spiders were collected from Liberty and Patuxent. As in 1981, the smallest spiders that could be found were removed, but they were collected two weeks later in the season. On 21 July I collected 41 immature spiders from Patuxent and 80 from Liberty. As in the previous two years, these spiders were also the progeny of spring adults, judging from the minimum time elapsing from maturity to hatching of progeny from the first egg sac (19-21 days; unpubl. data).

In all three years the collected spiders were reared in individual containers with a super-abundance of fruit flies. Although in nature the developmental rate of some juveniles might be limited by a shortage of prey, I provided a surplus of food in order to uncover the developmental potential of each individual. In 1980-81 rearings were done in the laboratory under natural photoperiod. In 1982 the juveniles were reared on the porch at Patuxent. 
Statistical analyses of the results of all studies were done with the UCLA BMDP programs, converted for use on Cyber computers by the Northwestern University Computing Center.

\section{RESULTS}

\section{Phenological Patterns in Maryland Populations}

Two peaks in adult abundance each season characterized the Liberty population (Fig. 1). Seasonal changes in the size-composition of both populations, particularly at Liberty, were similar to those found in the Michigan study (Figs. 2, 3; Wise 1976). The persistence of relatively high numbers of immature stages during the summer, and the absence of intermediate stages at the end of June, provide evidence of a polymorphic phenology: some progeny of the spring adults apparently over-wintered as juveniles, whereas others developed rapidly and molted to adulthood between the end of July and the first part of September. Average adult carapace width was always significantly smaller in summer than spring (Table 1), additional evidence that summer-maturing adults developed rapidly within a single season and were not the offspring of the previous summer's adults.

Females that matured in the spring laid more, but smaller, eggs than summer-maturing spiders (Table 1). Fecundity differences such as these could reflect different seasonally adaptive reproductive behaviors, or more simply, could have resulted entirely from reproductive parameters being correlated with female size. This possibility was examined. Analysis of the 1982 Patuxent data revealed statistically significant correlations between number of eggs in the first sac, egg diameter and female carapace width. Stepwise multiple linear regression of the pooled seasonal data indicated that number of eggs was significantly related to both female size and mean egg size $(\mathrm{R}=.52)$. Most of the variation in number of eggs laid could be explained by the correlation with carapace width; addition of egg size as an independent variable increased the value of $\mathrm{R}$ by only .05 . In a similar analysis with egg size as the dependent variable, egg number was the only statistically significant independent variable. Seasonal differences in reproductive parameters were then reexamined by comparing the adjusted means through ANCOVA of the appropriate regression equations. Differences between spring 

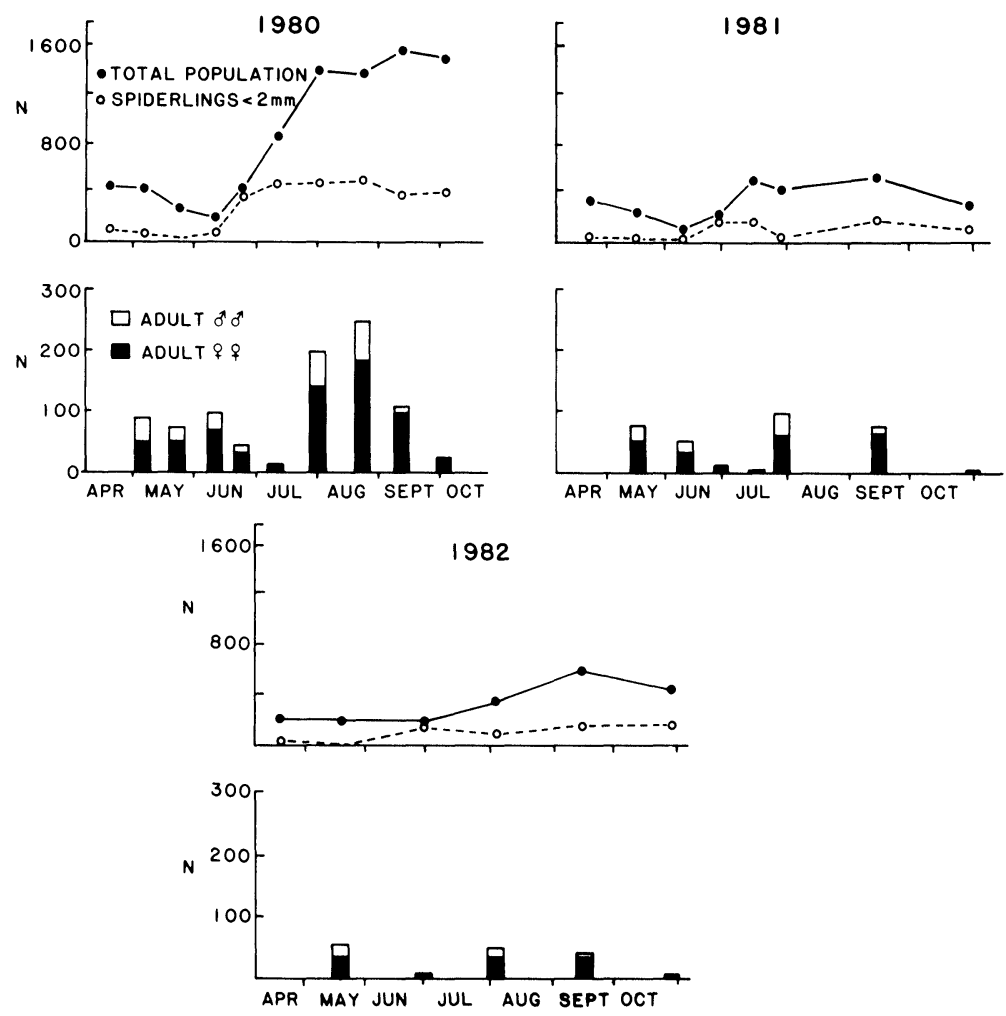

Figure 1. Seasonal and yearly changes at the Liberty site in density of spiderlings, adults and all stages combined. Numbers on the 13 marked areas are pooled. Changes in numbers are directly related to changes in population density because these same areas were censused each date. Although censuses were not conducted as frequently in 1982, they were made often enough to reveal a pattern similar to that of previous years: scarcity of adults at the end of June and an increase by early August.

and summer in number of eggs reflected seasonal differences in female size and egg size. However, the eggs laid by summer females were significantly larger than spring eggs even after correction had been made for the negative correlation with egg number (Table 2). The correlation between mean egg diameter and mean hatchling size for 46 summer females in 1982 was $0.51(\mathrm{p}<.001$, df $=44)$.

The structures of the Liberty and Patuxent populations differed on the same date (Fig. 3). Peaks in adult abundance occurred earlier 

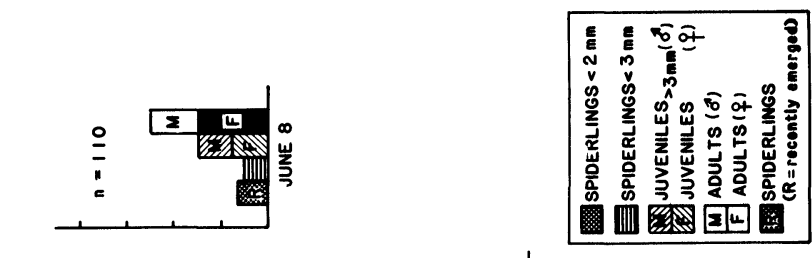

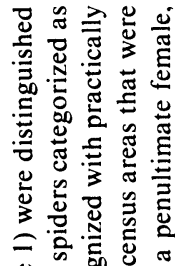

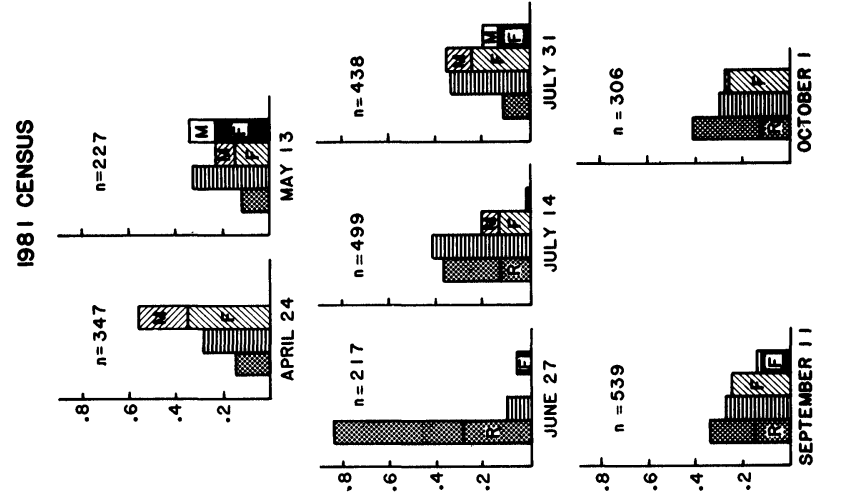

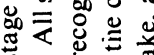

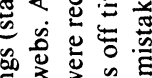

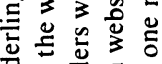

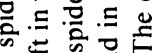

की के

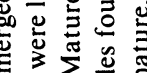

हैं $\frac{0}{\pi}$

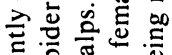

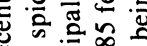

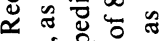

- 话范

증ㅇㅇ

뭉 응

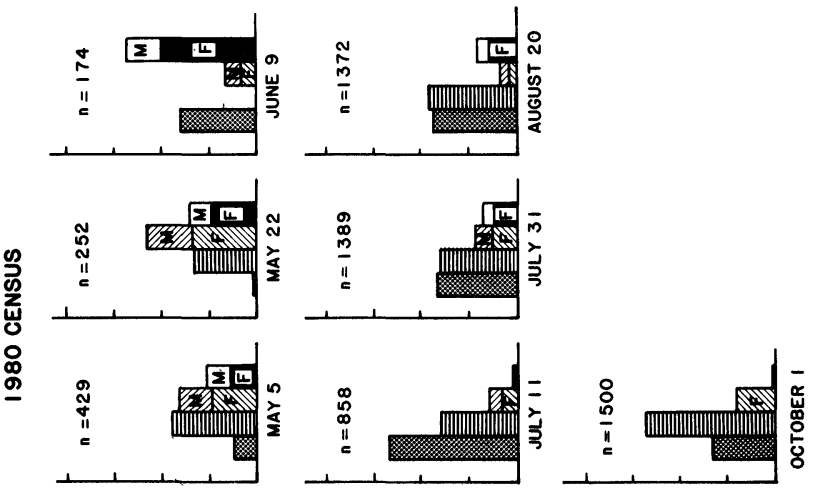

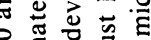

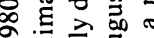

的㐫示市

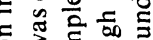

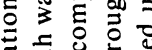

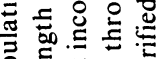

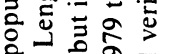

추의

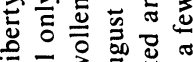

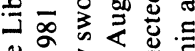

ฐ

ธ

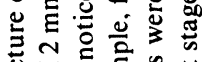

ป

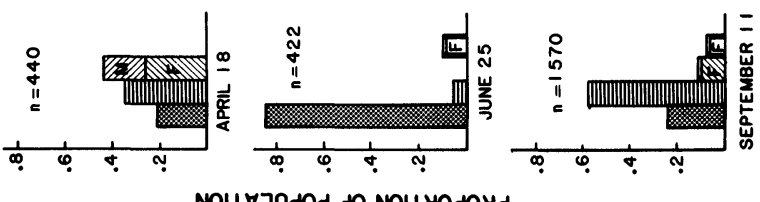

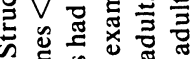

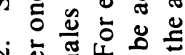

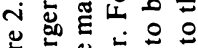

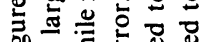

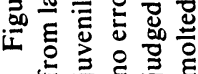




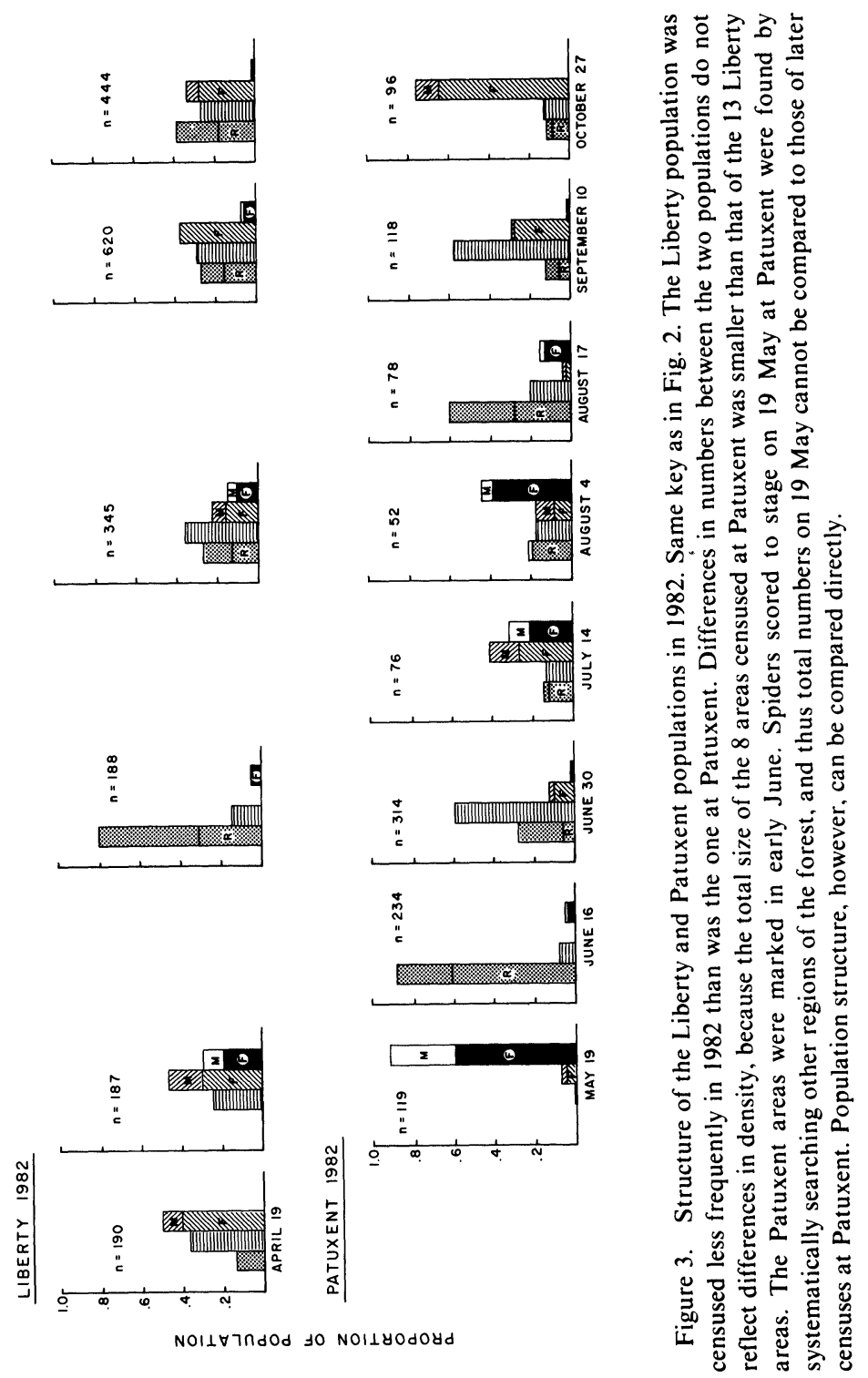


Table 1. Differences between spring and summer in size at maturity and reproductive parameters of spiders from Patuxent and Liberty populations. Means \pm s.e. are given with sample sizes in parentheses. The Bonferroni Multiple Comparison Test was used to examine the significance of seasonal differences for the Liberty population in 1980, and for Patuxent in 1981 and 1982. Differences between spring and summer in carapace width, egg number and egg size were all significant at $\mathrm{p}<$ .01 or greater. Means did not differ significantly between areas within the same season and year. Means also did not differ significantly between years, with the exception of male carapace width in the Liberty population between the springs of 1980 and $1981(\mathrm{p}<.01)$.

\begin{tabular}{|c|c|c|c|c|c|c|c|c|}
\hline & & \multicolumn{4}{|c|}{ SPRING } & \multicolumn{3}{|c|}{ SUMMER } \\
\hline & & \multicolumn{2}{|c|}{ Liberty } & \multicolumn{2}{|c|}{ Patuxent } & \multirow{2}{*}{$\begin{array}{c}\text { Liberty } \\
1980\end{array}$} & \multicolumn{2}{|c|}{ Patuxent } \\
\hline & & 1980 & 1981 & 1981 & 1982 & & 1981 & 1982 \\
\hline \multirow[t]{9}{*}{ Females } & Carapace $(\mathrm{mm})$ & 1.36 & 1.33 & 1.42 & 1.40 & 1.15 & 1.18 & 1.22 \\
\hline & & \pm .01 & \pm .01 & \pm .02 & \pm .01 & \pm .01 & \pm .01 & \pm .01 \\
\hline & & $(52)$ & $(27)$ & (35) & (93) & $(52)$ & (71) & $(48)$ \\
\hline & Number of eggs, & & 63 & & 66 & & 50 & 49 \\
\hline & first sac & & \pm 6 & & \pm 3 & & \pm 3 & \pm 3 \\
\hline & & & (9) & & $(56)$ & & $(15)$ & (34) \\
\hline & Egg diameter, & .610 & .618 & .597 & .603 & .653 & .649 & .641 \\
\hline & first sac $(\mathrm{mm})$ & \pm .003 & \pm .007 & \pm .003 & \pm .005 & \pm .004 & \pm .006 & \pm .007 \\
\hline & & $(44)$ & $(25)$ & $(30)$ & $(57)$ & (19) & $(17)$ & $(35)$ \\
\hline \multirow[t]{3}{*}{ Males } & Carapace $(\mathrm{mm})$ & 1.57 & 1.47 & 1.55 & & & 1.29 & 1.25 \\
\hline & & \pm .01 & \pm .02 & \pm .03 & & & \pm .02 & \pm .05 \\
\hline & & (10) & (19) & (11) & & & $(32)$ & (9) \\
\hline
\end{tabular}

in the season at Patuxent. For example, on 19 May 1982 only $30 \%$ of the Liberty population was mature, whereas at Patuxent over 90\% were adults. Also, mature spiders comprised a greater proportion of the summer population at Patuxent, suggesting that more progeny of spring adults developed rapidly at Patuxent than at Liberty. At the end of the season more of the population consisted of older juveniles at Patuxent than at Liberty. The accelerated phenology of the Patuxent population may have resulted, at least partly, from warmer web-site temperatures at this lower-elevation site (Table 3). The relative proportion of adults in the population throughout the season at Liberty more closely resembled the pattern in Michigan than did the pattern at the Patuxent site.

\section{Field Experiment}

On Day 0 (21 July) a total of 238 immature spiders, stages 2-4, occupied webs on the units. By the middle of September the total 
Table 2. Comparison of spring and summer fecundity parameters by ANCOVA. $*=p<.05 ;{ }^{* *}=p<.01$.

\begin{tabular}{|c|c|c|c|}
\hline \multicolumn{4}{|c|}{ Number of Eggs in First Sac } \\
\hline Source & D.F. & M.S. & $\mathrm{F}$ \\
\hline Equality of Adj. Means & 1 & 295 & .82 \\
\hline Zero Slope & 2 & 2305 & $6.45^{* *}$ \\
\hline Error & 79 & 357 & \\
\hline Equality of Slopes & 2 & 730 & 2.10 \\
\hline Error & 77 & 348 & \\
\hline \multicolumn{4}{|l|}{ Adjusted Means ( \pm s.e.) - } \\
\hline Spring: $\quad 61 \pm 3$ & & & \\
\hline Summer: $\quad 56 \pm 4$ & & & \\
\hline \multicolumn{4}{|c|}{ Egg Diameter $(\mathrm{mm})$, First Sac } \\
\hline Source & D.F. & M.S. & $\mathrm{F}$ \\
\hline Equality of Adj. Means & 1 & 152.6 & $11.13^{* *}$ \\
\hline Zero Slope & 1 & 56.2 & $4.10^{*}$ \\
\hline Error & 87 & 13.7 & \\
\hline Equality of Slopes & 1 & 4.8 & .34 \\
\hline Error & 86 & 13.8 & \\
\hline \multicolumn{4}{|l|}{ Adjusted Means ( \pm s.e.)- } \\
\hline Spring: $\quad .606 \pm .006$ & & & \\
\hline Summer: $.638 \pm .007$ & & & \\
\hline
\end{tabular}

number of immatures occupying all eight units was slightly over 100 (Fig. 4). All appeared to be younger than the penultimate instar, judging from the absence of significant swelling of male palps and the undeveloped female external genitalia. During the experiment 39 very small juveniles were removed from the populations. These spiders were obvious immigrants, most likely the progeny of summer-maturing adults. The disappearance of immature spiders during August coincided with the appearance of adult males and females (Fig. 4). The rate of appearance of mature spiders of both sexes declined in September; no mature males appeared on the units after 1 September.

Supplementing the food supply did not affect numbers of immature or mature spiders on the units, nor did providing additional prey influence size at maturity. During the experiment mean numbers per unit and linear dimensions of removed adults were practically identical for the supplemented and control populations. Only $36 \pm 2 \%$ of the spiders accepted the additional prey during the 
Table 3. Web-site temperatures. Means \pm s.e. with number of web sites measured in parentheses.

\begin{tabular}{lcccc}
\hline & \multicolumn{2}{c}{ Shady Sites } & \multicolumn{2}{c}{ Sunny Sites } \\
& Patuxent & Liberty & Patuxent & Liberty \\
\hline 24 May & $20.2 \pm .2$ & $18.6 \pm .1$ & $21.8 \pm .6$ & $19.6 \pm .2$ \\
& $(30)$ & $(57)$ & $(10)$ & $(4)$ \\
8 June & $24.8 \pm .3$ & $23.5 \pm .1$ & $27.2 \pm .4$ & $24.1 \pm .3$ \\
& $(13)$ & $(54)$ & $(7)$ & $(14)$ \\
\hline
\end{tabular}

first feeding round each day, suggesting that the majority of immature spiders was not experiencing a shortage of prey.

Many adults that appeared during the experiment undoubtedly were immigrants, as were some of the juveniles present in September. However, a significant fraction of the immature spiders on the units in September was likely part of the original cohort, since small spiders that were obvious immigrants were removed continuously during the experiment. Clearly many adults were immigrants, as the number appearing exceeded the decline in number of immature spiders. However, substantial numbers of penultimate stages appeared on the units during the first few weeks, indicating that many of the adults did develop from spiders that had been added to the units. Thus the immature filmy dome spiders added to the units in July apparently had one of two fates. Some matured by August or September, whereas the remainder were still immature by the middle of September and would not mature until the following spring.

\section{Rearing Studies: Field-Collected Juveniles}

All 47 juveniles removed from the population at Liberty in 1980 had matured by the end of August. These appeared to have been stage 3 or older when collected on 1 July.

The following year not all survived to the end of the summer, probably because smaller instars were collected. Over half $(65 \%)$ of the immatures collected in 1981 did survive, and all were adult by the end of August (Fig. 5).

In 1982 the populations were sampled 2 weeks later in July. Many of these juveniles had not matured by the end of the season. The total number that had either matured or were still alive as immatures by mid-September was 106 (86\% of the number collected); $39 \%$ of these spiders were still immature. The developmental status 


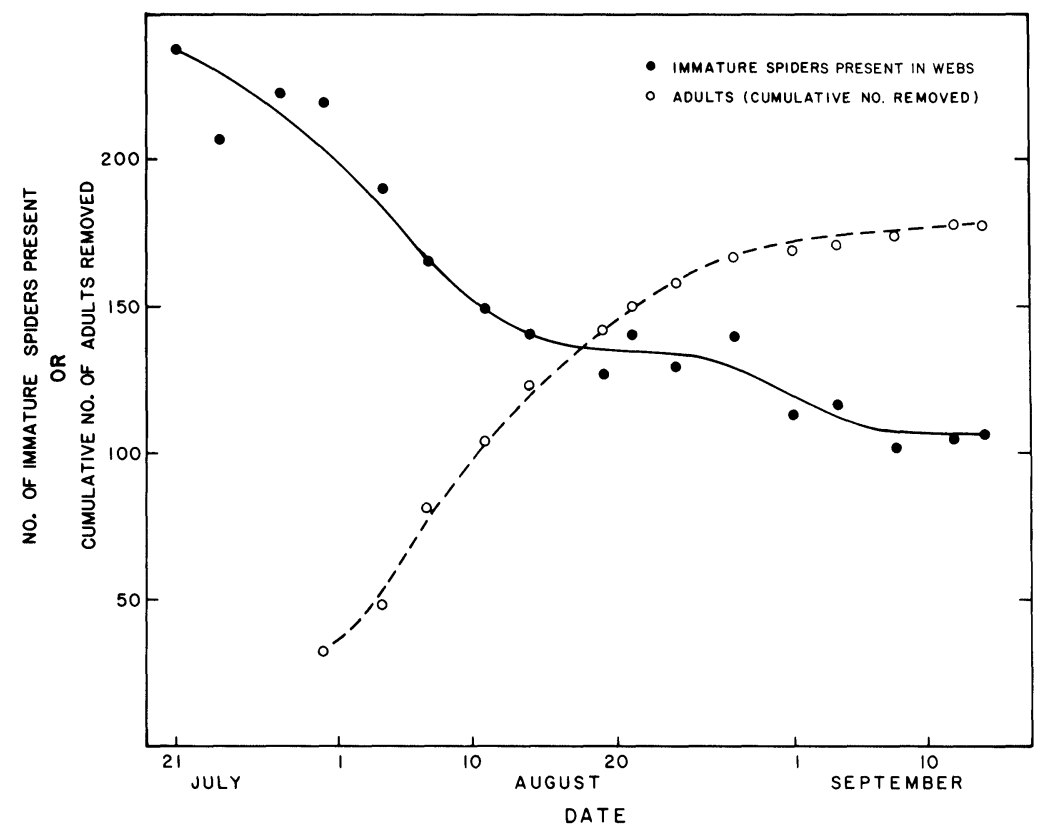

Figure 4. Numbers of immature spiders present in webs and cumulative numbers of adults removed during the 1981 field experiment. Not included are the obvious immigrants: juveniles smaller than those that were present the previous census (these were removed) and adults that appeared during the first week.

of spiders at this time of the season accurately predicts their state of maturity at the end of the season for two reasons: 1) In nature newly matured spiders do not appear after mid-September; 2) all but one of the immatures collected in 1982 that did mature that season completed the adult molt by 25 August. The one exception was a female that matured on 9 September.

When collected in July, juvenile spiders from Patuxent were more developed than those collected from Liberty and were more likely to have molted to adulthood by September (Fig. 6). A significantly greater proportion of the spiders from Patuxent was mature $(31 / 41=.76)$ than from Liberty $(34 / 65=.52)\left(\chi^{2}=5.76, \mathrm{p}<.05\right)$. The mean date on which the spiders molted to the adult stage was 6 August for those from Patuxent and 15 August for the Liberty spiders. Although spiders that were larger when collected were more likely to have matured, the correlation with stage and future 


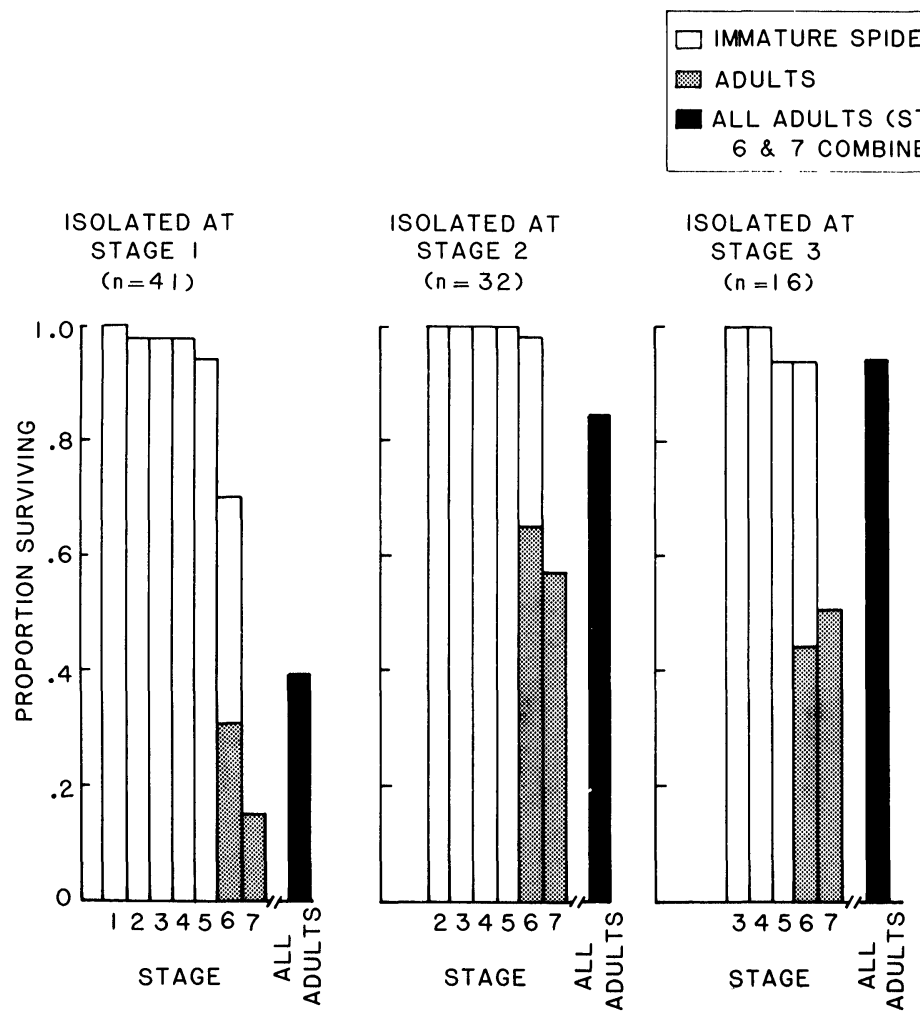

Figure 5. Development of immature spiders collected from the Liberty population on 6 July 1981 and reared in the laboratory. All had either matured or died by the end of August.

rate of development was not perfect. A few of the more advanced juveniles ( $\geqslant$ stage 3 ) survived but failed to mature during the 1982 season (Table 4).

\section{Discussion}

Maryland populations of the filmy dome spider exhibit a polymorphic life history pattern similar to that discovered in a more northern population in Michigan (Wise 1976). The phenology of the Liberty population more closely resembled that in Michigan than did the pattern at Patuxent, though data suggest considerable yearto-year variation at the latter site. This research has also furnished 


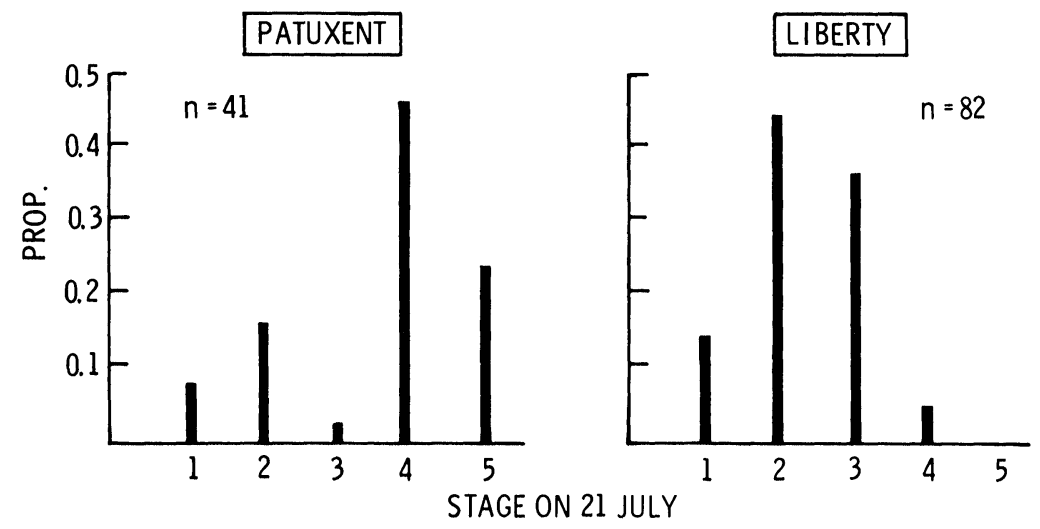

DEVELOPMENTAL STATUS IN MID-SEPTEMBER:

$\begin{array}{lcc}\text { NO. MATURED } & \text { PATUXENT } & \text { LIBERTY } \\ \begin{array}{c}\text { NO. IMMATURE ( alive ) } \\ \text { TOTAL ( } \% \text { of no. } \\ \text { collected })\end{array} & 10 & 31 \\ & 41(100 \%) & 65(79 \%)\end{array}$

Figure 6. Development of immature spiders collected from the Patuxent and Liberty populations on 21 July 1982 and reared on the porch at Patuxent. The bar graph indicates the estimated stages of the spiders when collected. Below the graph is summarized the number of spiders that either had matured by mid-September or were immature and still alive at that time.

direct proof of the previously proposed interpretation of the observed phenology.

\section{Causes of Variable Development in the Filmy Dome Spider}

The life history variation existing within Maryland populations of the filmy dome spider does not result from a genetic polymorphism (Wise, submitted). Instead, most of the variation appears to be environmentally induced, resulting from the response of a plastic phenotype to variation in proximate limiting factors.

Laboratory studies of other spiders have demonstrated extensive phenotypic plasticity in developmental rate, size at maturity and fecundity in response to variation in food supply and physical con- 
Table 4. Estimated stages, when collected from natural populations on 21 July 1982, of spiders that were alive as immatures in mid-September or that had matured by then. Stages were estimated by comparing tibia lengths to a distribution derived from a previous laboratory rearing study (unpubl). A. Numbers in each stage on 21 July that had matured. B. Numbers in each stage on 21 July that were immature and alive in September. All spiders that matured before winter had done so by mid-September.

\begin{tabular}{|c|c|c|c|c|c|}
\hline & \multicolumn{5}{|c|}{ Stage in July } \\
\hline & 1 & 2 & 3 & 4 & 5 \\
\hline \multicolumn{6}{|l|}{ A. Matured } \\
\hline Patuxent & & 2 & 1 & 19 & 9 \\
\hline Liberty & & 6 & 25 & 3 & \\
\hline Total & & 8 & 26 & 22 & 9 \\
\hline \multicolumn{6}{|l|}{ B. Immature } \\
\hline Patuxent & 3 & 5 & & 1 & 1 \\
\hline Liberty & 9 & 19 & 2 & 1 & \\
\hline Total & 12 & 24 & 2 & 2 & 1 \\
\hline
\end{tabular}

ditions (Browning 1941, Jones 1941, Deevey 1949, Turnbull 1962, 1965). Rearing studies with hatchlings of Patuxent females show that food supply can affect rates of growth and development of the filmy dome spider (Wise, submitted). Martyniuk has also demonstrated the plastic response of developmental rate in $N$. radiata to variations in prey abundance in a laboratory study, and in a field experiment has established that local differences in prey abundance influence web-site selection and tenacity in this species (Martyniuk 1983). Although the 1981 field experiment at Patuxent provided no evidence of food limitation, other research has demonstrated that natural prey levels can limit the fecundity and growth rate of filmy dome spiders in nature (Wise 1975). Differences in temperature between web sites also possibly contribute to intra-populational variation in developmental rate. Comparison of the phenologies at Patuxent and Liberty provides indirect evidence of the effect of temperature on developmental rate, since the stage of development was accelerated at the warmer location.

Environmentally induced variation in growth and development of filmy dome spiders partially explains their maturing at different times during the spring. In addition, seasonal selective constraints associated with the timing of reproduction by summer-maturing adults (to be discussed later) have apparently interacted with this variation to expand the spring reproductive period even further. 
The result is a life history in which the timing of reproduction is the major variable determining the developmental patterns of the offspring.

In Maryland, spring-maturing $N$. radiata mate and lay eggs for 8-10 weeks, from May through early July. Offspring of these adults thus emerge from egg sacs over a considerable span of time. Spiderlings that hatch from sacs laid by early-maturing adults have time to complete development and reproduce before winter. Many of those that hatch from egg sacs laid at the end of the spring reproductive period have a different fate. While some may mature by the end of the season, not all develop that rapidly. Those that emerge from the later egg sacs, or that capture insufficient prey or construct webs at sites with low temperatures, over-winter as juveniles and become the early-maturing adults of the following spring. Populations exhibiting this life history pattern complete approximately three generations every two years.

The degree of polymorphism exhibited by a population appears to vary with the length and average temperature of the growing season. Almost all $N$. radiata at the Patuxent site completed two generations in 1982. However, at the higher, cooler Liberty site, and in the Michigan population studied previously (Wise 1976), a significant number of the offspring of spring females over-wintered as immatures and did not become adult until the next year. The summer peak of adults is reduced in $N$. radiata populations in the Catskill Mountains of New York (Martyniuk, pers. comm.). These patterns lead to the prediction that extreme southern populations of the filmy dome spider are consistently bivoltine, whereas populations at higher latitudes and elevations are univoltine. A substantial number of populations, perhaps most, likely show a life cycle that is intermediate between an annual and a biannual, or bivoltine, pattern.

The extent of the life history polymorphism may vary yearly at the same site, judging from experiences at Patuxent 1981-82. In the 1981 field experiment a substantial fraction of the spiders was still immature at the end of the season, yet in the following year very few progeny of spring adults failed to reach adulthood by August. In 1982 almost an entire day of searching at Patuxent was required to locate the 41 juveniles for the rearing experiment, yet in the previous year the earlier developmental stages had been much more abundant the same time of the season. Possibly this difference in age 
structure resulted from poorer survival of the later egg sacs in 1982 compared to 1981, in addition to environmentally caused differences in developmental rates of hatchlings. These suggestions are speculative, as no data exist from which the causes of this particular yearly difference can be deduced.

\section{Variable Phenologies in Other Spiders}

Environmentally induced variable phenologies occur in other spiders (e.g. Dondale 1961, Almquist 1969, Toft 1976, 1983). Frequently this variation is correlated with differences in length and average temperature of the growing season, either between years or along latitudinal and elevational gradients. However, most examples involve shifts not between univoltine and bivoltine patterns, but between annual and biennial life cycles. In fact, the occurrence of two generations per year has not been reported often for spiders. Juberthie (1954) concluded that several species he studied had bivoltine life cycles, though his evidence came solely from laboratory rearings. At least one of the species that he studied apparently completes only one generation per year in nature (Enoplognatha ovata; Seligy 1971). However, examination of areas warmer than those studied by Seligy might reveal a biannual phenology for E. ovata. Bonnet (1930, cited by Levy 1970) found that Pirata piraticus probably produces two generations per year. Another wolf spider, Lycosa T-insignita, has a phenology similar to that of the filmy dome spider (Miyashita 1969). Two adult peaks occur, and as with $N$. radiata, adults that mature in the summer are smaller than spring-maturing individuals. Furthermore, apparently not all $L$. $T$ insignita complete two generations per year.

Possibly modified bivoltine life cycles are characteristic of many small spiders in temperate regions. Casual, non-systematic observations of the linyphiid Frontinella pyramitela (Walckenaer) suggest that this species may have two peaks in adult abundance each year (pers. obs.). The occurrence of two abundance peaks in a year, termed diplochronism by Tretzel (1961), occurs in several species of spiders (Toft 1976). However, Toft concluded that the phenomenon did not result from a mixture of biannual and annual life cycles for the species he studied in northern Europe, but instead occurred in species that had generation times of a year or longer. Conclusions about the ubiquity or rarity of both typical and modified bivoltine life cycles among temperate spiders must remain speculative until more evidence is gathered. 


\section{Adaptive Significance of $N$. radiata's Life History Plasticity}

Is the life history plasticity exhibited by individual $N$. radiata adaptive? In discussing the adaptive significance of developmental plasticity, Smith-Gill (1983) distinguished between developmental conversion and phenotypic modulation. Passive response of the organism to environmental variation constitutes modulation, which is not necessarily adaptive. Continuous phenotypic variation frequently characterizes this type of plasticity. In $N$. radiata, nonadaptive phenotypic modulation is expressed as the variation in size at maturity and fecundity within spring and summer populations attributable to different feeding histories or web-site temperatures. On the other hand, the filmy dome spider's variable phenology apparently involves a developmental switch, and is likely an example of adaptive developmental conversion.

Several features of $N$. radiata's phenology argue against phenotypic modulation as the only explanation for the variable developmental rates exhibited by this species. One major feature supporting the argument against modulation is the presence of two pronounced peaks in adult abundance. It appears that individuals do not develop at similar rates during the season, with cold weather or changing photoperiod simply arresting development of all stages equally. That is, while variables such as temperature affect developmental rate, the effects apparently depend upon both the stage of the individual and the time of the season. Further support for developmental conversion comes from the timing of the summer peak in adult abundance. Not only do no adults over-winter, but nearly all summer-maturing spiders have completed the adult molt by the end of August. Furthermore, some spiders continue to grow and molt for many weeks after the last maturation ecdysis has occurred, eventually maturing the next season at a larger size than those that became adult in August. This pattern constitutes strong evidence that a developmental switch has occurred earlier in the season, either in the earlier instars or perhaps as a result of the type of eggs laid by late-maturing spring females. The developmental fates of juveniles collected at different times is also evidence that such a conversion from rapid to slower development occurs well in advance of the end of the season. Additional evidence comes from a rearing study that found marked differences in the developmental fates of hatchlings emerging at different times during June and July (Wise, submitted). 
Perhaps adult $N$. radiata cannot adapt physiologically to cold. Thus winter mortality of adults might be one selective factor that has favored maturation well in advance of winter. Another possible selective factor might be the lower rate of survival over winter of smaller juvenile $N$. radiata (Martyniuk 1983; Wise, unpubl. data). The peak of egg-laying by the second generation occurs early enough for most hatchlings to emerge and complete one or more molts before the end of the growing season. Their chances of surviving the winter are greater than if they had emerged from egg sacs laid at the end of the season. Since egg size and hatchling size are positively correlated, the fact that summer females lay larger eggs than spring females also suggests the increased importance of size to juvenile survival later in the season.

Those spiderlings that postpone maturation tend to mature at a larger size, which leads to higher female fecundity. Increased size may also improve the mating success of males, since they compete aggressively for females (pers. obs.). These and other aspects of $N$. radiata's life history suggest that slower development is not unadaptive within the constraints seasonality imposes upon the timing of reproduction, and as part of a phenotype that also can develop more rapidly if environmental conditions are favorable. The hypothesis that the developmental plasticity of the filmy dome spider involves a developmental switch in the middle of the summer is tenable, but requires further testing. In particular, what are the proximate cues involved in the switch? Research on developmental rates of other spiders suggests that changing photoperiod may be important (Schaefer 1976, 1977). How do seasonal cues interact with the current physiological state and developmental history of the individual? What is the non-genetic maternal contribution to the developmental fate of hatchlings?

In addition to answering questions such as these, it would be fruitful to determine whether or not the type of developmental flexibility exhibited by $N$. radiata has evolved in other spiders. Such a life history pattern may be more widespread among temperate spiders than is now realized.

\section{SUMMARY}

A polymorphic phenology, apparently characterized by rapid and slow developers among the progeny of spring-maturing adults, was found in two Maryland populations of the filmy dome spider, $N$. 
radiata. Seasonal changes in the size-composition of the populations were similar to those found earlier in a Michigan population (Wise 1976). A field experiment and rearings of juveniles collected at different times of the season confirmed the presence of rapid and slow developers. Furthermore, these studies, in conjunction with the results of other research (Wise, submitted), established that variation in the timing of reproduction by spring-maturing females is the major contributor to the variable developmental rates of young spiders during the summer.

Progeny of early-spring maturing females develop rapidly, mature by August and deposit egg sacs before the end of the season. Hatchlings from these sacs over-winter as early instars and mature late the following spring. Progeny of these late-spring maturing individuals do not develop to maturity within the same season. Instead, these offspring over-winter as juveniles and mature early the next spring. On average, then, three generations are completed every two years in these populations.

These two paths of development represent two alternatives, determined primarily by the seasonal timing of reproduction, but subject to the influences of other environmental variables. Thus the pattern as described is idealized. The actual fraction of spiderlings developing along each path varies between sites, and even between years at the same site, in response to differences in environmental factors such as web-site temperature, length of the growing season and possibly prey abundance. In different situations anywhere from a few to most of the progeny of late-spring maturing individuals may develop to maturity in the same season that they hatched. Some northern populations of $N$. radiata may be mainly univoltine, whereas populations at the southern limits of the species' range may be entirely bivoltine.

The phenology exhibited by Maryland and Michigan populations of $N$. radiata is intermediate between an annual and a bivoltine life cycle. This type of phenology has not been reported often for spiders. Whether or not this pattern is unusual, or is common but undocumented, remains to be established.

\section{ACKNOWLEDGEMENTS}

K. Cangialosi worked on the project from the beginning and made innumerable contributions to its successful completion. D. 
Debinski, J. Nair, L. Scott and L. Schultz also contributed crucial field and laboratory assistance during one or more seasons. Undisturbed research sites and laboratory facilities for much of the research were provided by the Patuxent Wildlife Research Center, U.S. Department of the Interior. Their continued support is gratefully acknowledged. The University of Maryland Computer Science Center furnished support for data analysis. D. Gill, J. Martyniuk and P. Reillo made helpful comments on a earlier version of the manuscript. This research was supported by National Science Foundation Grants DEB 79-11744 and DEB 81-19309.

\section{Literature Cited}

Almquist, $\mathbf{S}$.

1969. Seasonal growth of some dune-living spiders. Oikos 20: 392-408. BONNET, P.

1930. La mue, l'autotomie et la régéneration chez. les Araignées avec une étude des Dolomèdes d'Europe. Thèse Faculte des Sciences de Toulouse 44: 1-464 (cited in Toft 1976).

BROWNING, H. C.

1941. The relations of instar length to the external and internal environment of Tegenaria atrica (Arachnida). Proceedings of the Zoological Society of London, Series A 111: 303-317.

Deevey, G. B.

1949. The developmental history of Latrodectus mactans (Fabr.) at different rates of feeding. American Midland Naturalist 42: 189-219.

Dondale, C. D.

1961. Life histories of some common spiders from trees and shrubs in Nova Scotia. Canadian Journal of Zoology 39: 777-787.

JONES, S. E.

1941. Influence of temperature and humidity on the life history of the spider Agelena naevia Walckenaer. Annals of the Entomological Society of America. 34: 557-571.

JuBERTHIE, C.

1954. Sur les cycles biologiques des Araignées. Bulletin de la Societe Historie Naturelle de Toulouse 89: 299-318.

LEVY, G.

1970. The life cycle of Thomisus onustus (Thomisidae: Araneae) and outlines for the classification of the life histories of spiders. Journal of Zoology (London) 160: 523-536.

MarTyNiUK, J.

1983. Aspects of habitat choice and fitness in Prolinyphia marginata (Araneae: Linyphiidae): Web-site selection, foraging dynamics, sperm competition, and overwintering survival. Unpublished Ph.D. Thesis. State University of New York at Binghamton. 
Miyashita, $K$.

1969. Seasonal changes of population density and some characteristics of overwintering nymph of Licosa T-insignita Boes. et str. (Araneae: Lycosidae). Applied Entomology and Zoology 4: 1-8.

SCHAFFER, M.

1976. Zur Steuerung der Jahresrhythmik bei Spinnen (Arachnida: Araneae). Entomologica Germanica 3: 125-129.

1977. Winter ecology of spiders (Araneida). Zeitschrift für angewandte Entomologie 83: 113-134.

Seligy, V. L.

1971. Postembryonic development of the spider Enoplognatha ovata (Clerck) (Araneae: Theridiidae). Zoological Journal of the Linnean Society 50: 21-31.

Smith-Gil.., S. J.

1983. Developmental plasticity: Developmental conversion versus phenotypic modulation. American Zoologist 23: 47-55.

ToFt, S.

1976. Life-histories of spiders in a Danish beech wood. Natura Jutlandica 19: 5-40.

1983. Life cycles of Meta segmentata (Clerck, 1757) and Meta mengei (Blackwall, 1869) in Western Europe (Arachnida: Araneae: Tetragnathidae). Verh. naturwiss. Ver. Hamburg (NF)26: 265-276.

TRETZi:, E.

1961. Bilogie, Okologie und Brutpflege von Coelotes terrestris (Wider) (Araneae. Agelenidae). Teil 1.: Biologie und Okologie. Zeitschrift für Morphologie Ókologie der Tiere 49: 658-745. Cited in Toft 1976.

TIRNBITL. A. L.

1962. Quantitative studies of the food of Linyphia triangularis (Clerck) (Araneae, Linyphiidae). Canadian Entomologist 94: 1233-1249.

1965. Effects of prey abundance on the development of the spider Agelenopsis potteri (Blackwell) (Araneae: Agelenidae). Canadian Entomologist 97: 141-147.

WISE, D. H.

1975. Food limitation of the spider Linyphia marginata: Experimental field studies. Ecology 56: 637-646.

1976. Variable rates of maturation of the spider, Neriene radiata (Linyphia marginata). American Midland Naturalist 96: 66-75.

Submitted. Evidence that developmental plasticity rather than genetic variation causes the variable phenology of the filmy dome spider. 

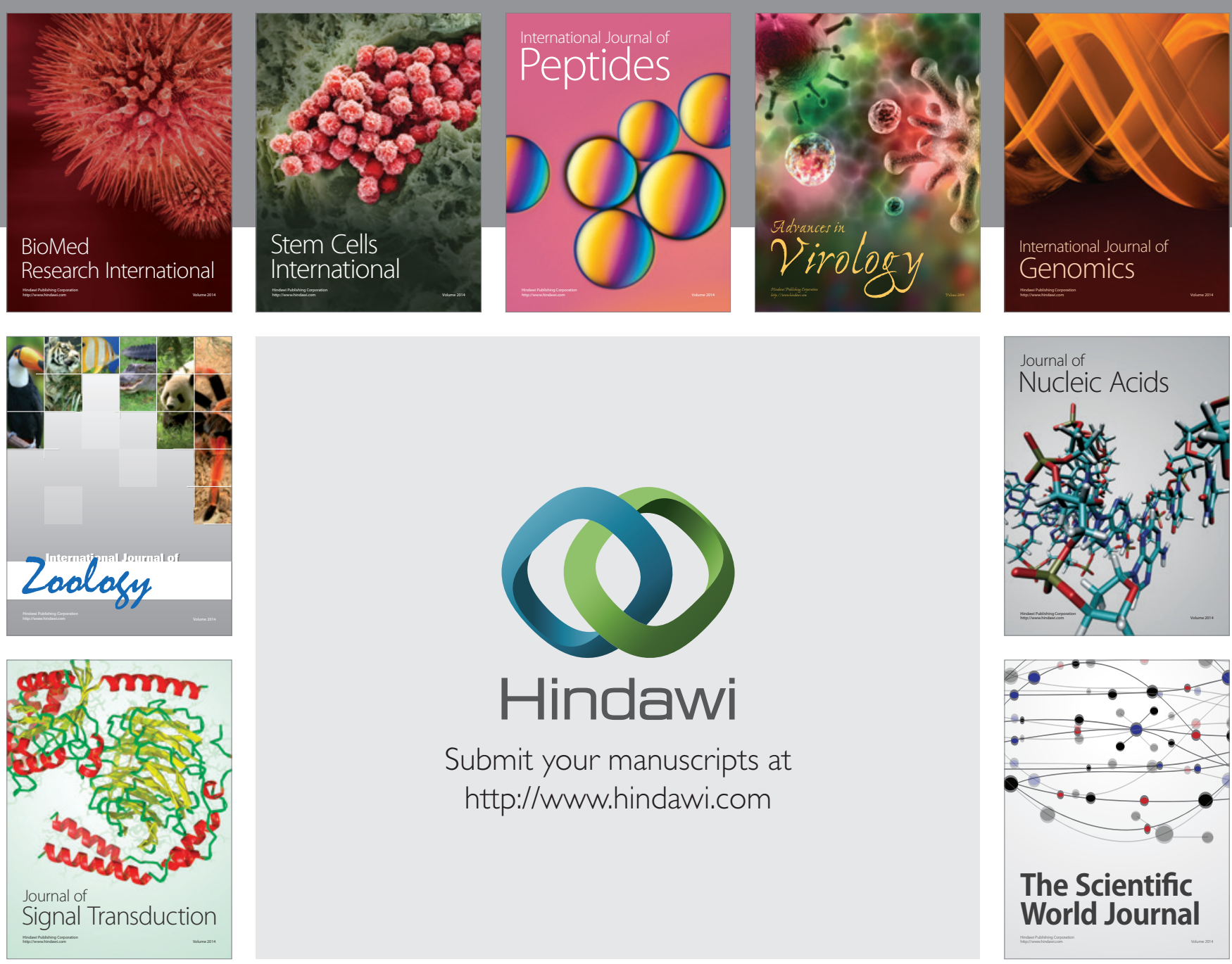

Submit your manuscripts at

http://www.hindawi.com
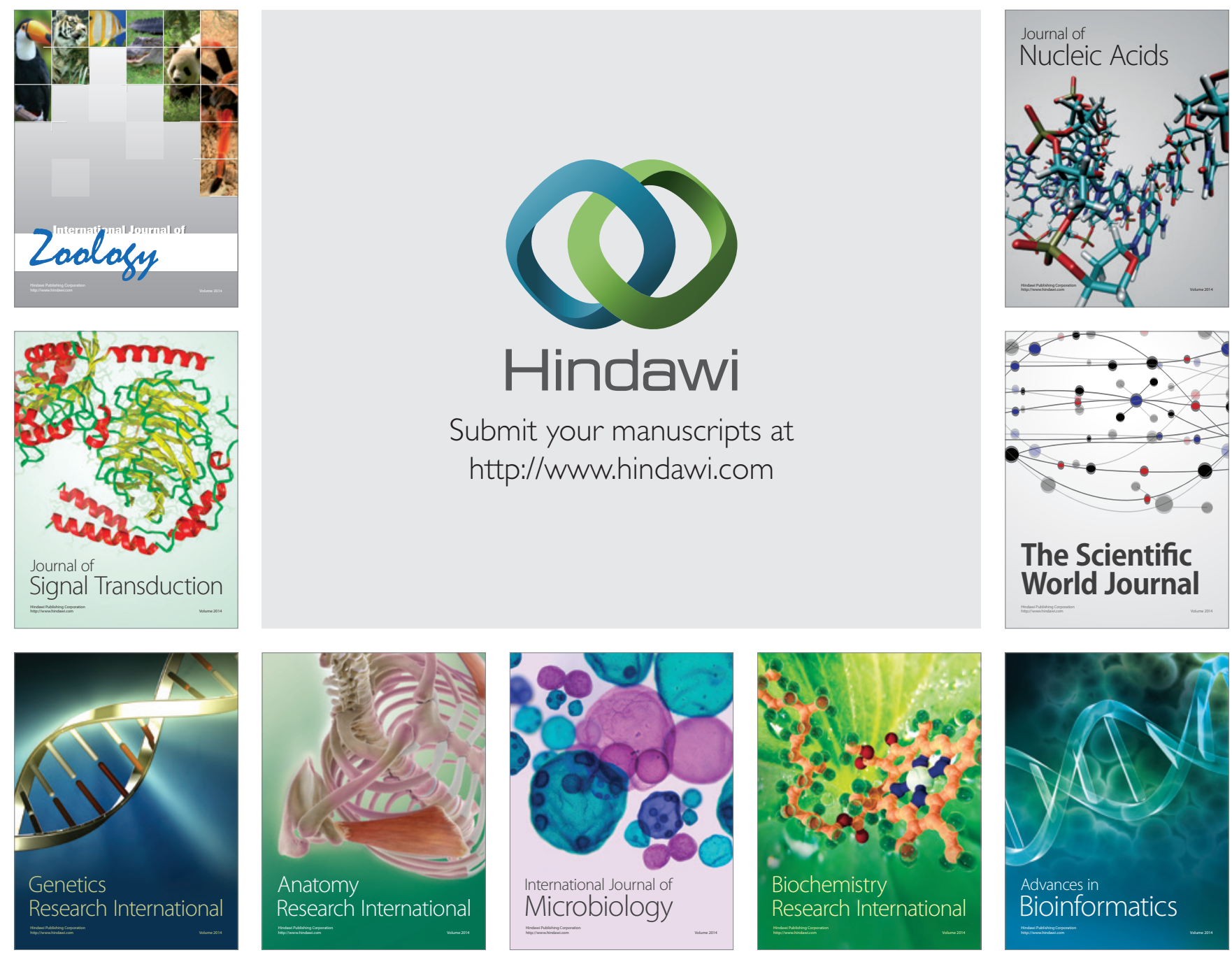

The Scientific World Journal
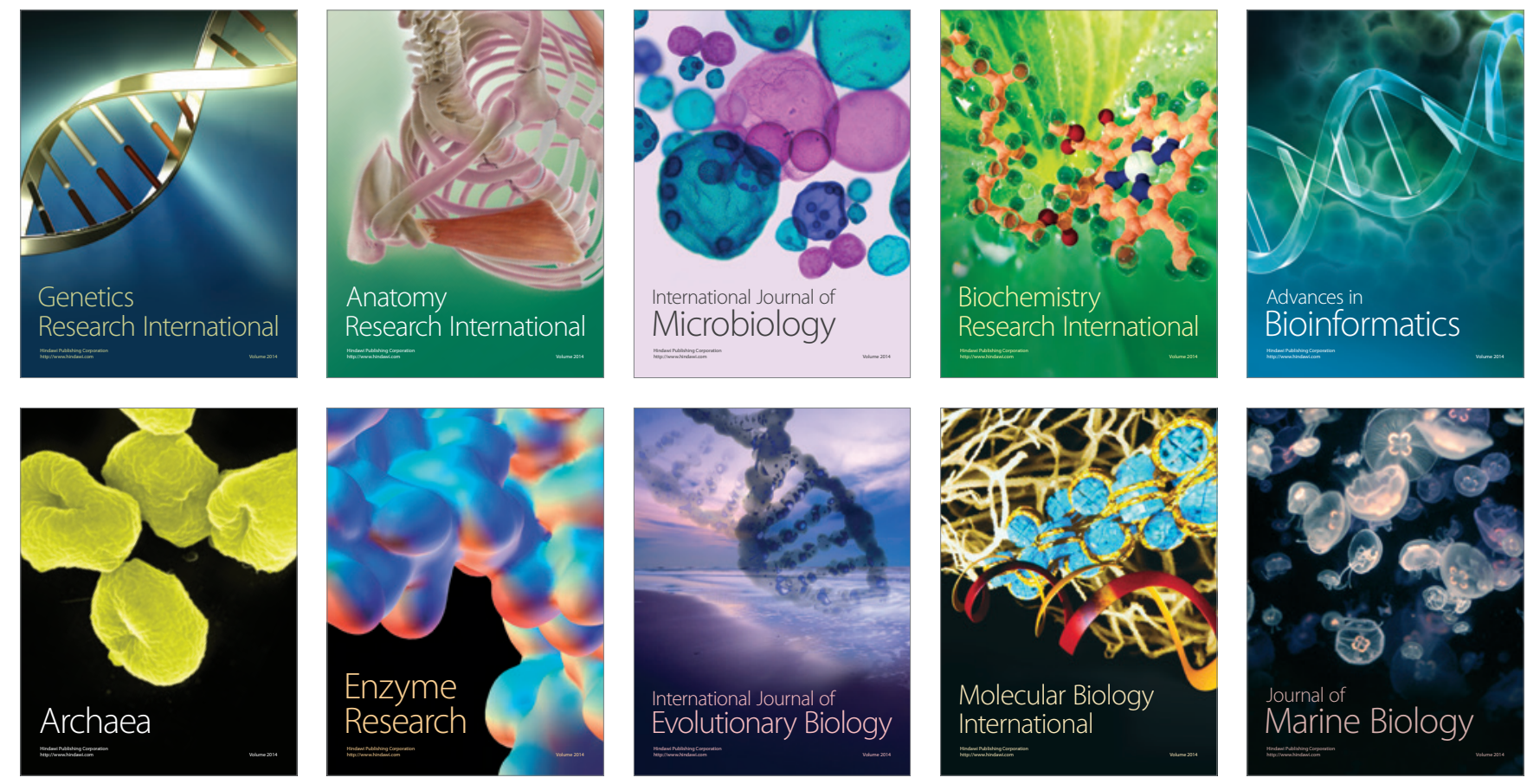